\title{
O fetiche da tecnologia e a teleologização da história: análise crítica do irracionalismo tecnológico
}

\section{The fetish of technology and the teleologization of history: critical analysis of technological irrationalism}

\author{
Rafael Rodrigo Mueller ${ }^{1}$
}

\begin{abstract}
RESUMO
O objetivo de nosso estudo foi analisar as diversas perspectivas sobre a tecnologia evidenciando um possível encadeamento histórico-ideológico entre autores considerados referências em suas apropriações acerca do tema. Para tanto, verificou-se a particularidade do objeto (tecnologia) em sua abstração (revisão teórica) no intuito de identificarmos o seu impacto na materialidade historicamente desenvolvida. Tendo em vista o amplo espectro que permeia a tecnologia e seus aspectos filosóficos, econômicos e sociais, tornou-se necessária a análise no âmbito ideológico que se mostra campo de disputa primordial pelo fato de tanto as vertentes pessimistas quanto as otimistas acerca da tecnologia não buscarem compreendê-la a partir de seu fundamento constitutivo ontológico. Sendo assim, o fetiche da tecnologia promovido por certos autores aqui analisados, proporciona as condições objetivas para a 'naturalização' do controle que o capital exerce sobre a força de trabalho, característica necessária para o processo de valorização do valor.
\end{abstract}

Palavras-chave: Fetiche da tecnologia. Capital. Ideologia.

\section{ABSTRACT}

The aim of our study was to analyze the different perspectives about technology indicating a possible linkage between historical and ideological authors considered references in its appropriations about technology. To this, we systematically checked the particularity of the object (technology) in its abstraction (theory revision) in order to identify its impact on the materiality historically developed. Given the broad spectrum that permeates the technology and its philosophical, economic and social aspects, it became necessary to analyze the ideological framework that is the main battle field, because both pessimistic and optimistic strands about the technology do not try to understand it from its ontological constitution foundation. So, the fetish of technology promoted by certain authors reviewed here provides the objective conditions for the "naturalization" of control that capital exerts on the labor force, a characteristic necessary for the process of appreciation of value.

Keywords: Fetish of technology. Capital. Ideology.

\footnotetext{
1 Graduado em Administração de Empresas pela Fundação Universidade Regional de Blumenau, mestre em Educação pela Universidade Federal de Santa Catarina e doutor em Educação pela UFSC. Atua principalmente no campo de estudos: Ciência, Tecnologia e Sociedade e Sociologia das Organizações. É professor do Programa de Mestrado Interdisciplinar em Organizações e Desenvolvimento da FAE-Curitiba.
}

Esta obra foi licenciada com uma Licença Creative Commons - Atribuição 3.0 Não Adaptada. 


\section{ELEMENTOS INTRODUTÓRIOS}

Nosso intento ao desenvolver esse estudo é o de analisar as diversas perspectivas que permeiam a tecnologia evidenciando um possível encadeamento histórico-ideológico entre autores que, numa primeira leitura, se mostraram divergentes quanto às suas concepções sobre tecnologia; porém, ao nos utilizarmos da lupa materialista histórica, no intuito de compreender as contradições inerentes ao próprio organismo sócio-metabólico do capital, verificamos no discurso e escritos de certos autores o caráter reformador, na melhor das hipóteses, do cotidiano das relações sociais capitalistas. A matriz conceitual desse concatenamento ideológico tem suas raízes históricas em uma visão de mundo em que a ciência e a tecnologia, ao serem elencadas como o motor da história por determinarem não só as relações de produção mas também as relações sociais, são dominadas pelo "fetiche da tecnologia". Mesmo aqueles que em alguma instância se posicionam criticamente frente à apropriação da tecnologia pelo modo de produção capitalista, comprometem sua análise por abdicarem, parcial ou totalmente, da relação entre tecnologia e capital e suas consequências sociais no que se refere à produção de mercadorias.

Nesse sentido, tornou-se imprescindível destacar como Álvaro Vieira Pinto, ao adentrar pelas leituras densas de Marx e por meio do materialismo históricodialético, conseguiu apreender com maior exatidão do que grande parte dos autores atuais, os nexos causais imprescindíveis para o desvelamento das relações sociais capitalistas que permeiam a análise da categoria tecnologia.

Apesar de estarem, num primeiro momento, organizados em duas categorias significativamente distintas, verificou-se que tanto os defensores acríticos quanto os críticos fatalistas pouco avançam em sua apreensão da categoria tecnologia e de sua relação com o processo de valorização do valor no sentido de transcendê-la. Este, certamente, foi o grande diferencial entre os autores analisados: o grau de verificação das contradições presentes na relação entre tecnologia e capital.

Dentre os autores abordados nesse estudo, há aqueles para os quais nos propusemos a tecer críticas radicais, como Martin Heidegger e Jürgen Habermas; aqueles para os quais encontramos algum problema ou limitação em sua abordagem frente à relação tecnologia e capital como Herbert Marcuse; e, finalmente, aqueles de cujas ideias corroboramos e que nos deram grande parte da 
sustentação teórico-metodológica - nesse caso, Álvaro Vieira Pinto e consequentemente Marx -, necessária para desvelarmos a relação existente entre a tecnologia e sua apropriação ideológica por parte do capital.

\section{HEIDEGGER E O HORROR TECNOLÓGICO}

A relação dialética entre a materialidade e subjetividade nos auxilia a compreender os extremos que compõem a discussão que iniciamos, qual seja, como as raízes filosóficas do individualismo relativista de Martin Heidegger e sua concepção fenomenológica anti-tecnológica dão sustentação para que se imponha uma teleologia à história imprescindível para uma apropriação da tecnologia ou - em uma perspectiva ontológica - da racionalidade humana, onde esta se torna um ente fetichizado que obscurece as relações sociais alienadas pelo movimento do capital. O horror frente à tecnologia e suas consequências sociais, segundo Heidegger, deu vazão a um dos extremos abordados por nossa discussão, que desemboca em uma das mais pobres compreensões acerca da tecnologia e que hoje ainda se faz presente, contribuindo diretamente para o fetiche da tecnologia: a tecnofobia.

Os escritos de Heidegger sobre a tecnologia e sua condição frente à sociedade moderna nos deram os elementos necessários para dirigirmos críticas ao autor em questão, por sua contribuição permanente a uma apropriação teórica que, como veremos no decorrer desse item, em sua essência, é inerentemente irracionalista. A desvinculação da técnica como parte fundamental para o salto qualitativo dado pelo homem em seu processo de desenvolvimento em ser social, da essência do seu ser, já é um problema sem solução em Heidegger. Conforme Brüseke (2007), o conceito de desocultamento técnico mostrou-se como um conceito crítico, pois era evidente o descontentamento de Heidegger com o percurso real da história humana, ainda mais nos tempos modernos e com o "[...] aceleramento da materialização, da uniformização, da funcionalização, da polarização sujeito-objeto, do cálculo, da imposição e da dominação, do produtivismo, do consumo e da substituição das coisas e do homem".

Um dos maiores problemas em que incorreu Heidegger, a nosso ver, é que a 'crítica' ao desocultamento técnico e suas conseqüências na sociedade moderna 
deveria ser dirigida, na verdade, ao estágio em que se encontravam desenvolvidas as relações produtivas capitalistas, e não à técnica em si. Ao se prender aos questionamentos metafísicos do ser, da existência, da ansiedade até a morte, temas de Ser e Tempo, e da decepção frente ao futuro da humanidade, particularmente na esperança depositada no nazismo, Heidegger se desprende da política e da história no intuito de se autopreservar. A seu ver as questões postas anteriormente seriam supra-históricas, onde a política, a economia ou a própria história em nada teriam a colaborar com o seu retorno ao 'ser'. "A esfera pública e a política democrática não tinham contribuição alguma a fazer para a realização da autenticidade" (HERF, 1993, p.128). A autenticidade, para Heidegger, seria o caminho contrário ao esquecimento do ser, que era proporcionado pela técnica moderna, a qual se mostrava mais hostil ao homem por meio das explosões nucleares no Japão (ou seja, a técnica ou racionalidade científico-tecnológica como ente auto-dirigido providenciava o afastamento do homem de sua essência). Isso é evidenciado por Brüseke (2007, p.24-25), ao afirmar que para Heidegger "a ciência tem um caráter intervencionista. Contrariando a sua própria autodefesa, que reclama neutralidade axiológica e a abstenção de juízos de valores para si, ela interfere na realidade conforme as necessidades da técnica". Critelli (2002, p.89) reforça a idéia de Heidegger de que a técnica afasta homem de sua essência autêntica:

\begin{abstract}
A interpelação produtora da técnica é sempre determinante do nosso agir, pensar e conduzir. A interpelação da técnica nos substitui em nossas decisões e ações. Substitui-nos em nossa responsabilidade, uma vez que ela nos oferece tudo já previamente delimitado. Substitui-nos naquilo que mais nos caracteriza em nossa humanidade, segundo Heidegger, que é o sermos do ser, cuidadores do ser.
\end{abstract}

Dois dos maiores mitos relacionados ao desenvolvimento científicotecnológico estão contidos nas afirmações anteriores: 1) a inerente 'neutralidade' da ciência e tecnologia; e 2) a tecnologia como um ente autônomo que se sobrepõe à sociedade. Novamente é relegada a técnica a autonomia para subjugar os homens, determinando suas ações, retirando por completo de nossos ombros quaisquer responsabilidades frente às mazelas que a sociedade é acometida; e opondo a técnica - anti-humana por natureza -, ao homem que tem em sua essência a cooperação e o bem-estar da humanidade.

Na visão de Heidegger, a técnica se torna a metafísica consumada, ou seja, é por meio de uma teleologia impingida à história que ele desenvolve a concepção do 'fim da história' ou 'não-história', pois conforme Miranda (2002) é o processo de Cad. de Pesq. Interdisc. em Ci-s. Hum-s., Florianópolis, v.12, n.101, p.171-198, ago/dez 2011 
tecnificação que não produz outra razão qual seja a razão instrumental. Sendo assim, quando Heidegger fala do acabamento (a consumação) da metafísica pela técnica, não significa que esta terminou, mas que realizou a verdadeira verdade do ente por sua calcularização, maquinização e tudo que configura a estrutura (gestell) de nossa época. Nada de essencial se pode esperar como novo que não a configuração essencial da estrutura da tecnificação.

Das potencialidades históricas contidas na relação entre o homem e a natureza e que já auxiliaram no decorrer dos tempos a humanidade a produzir milhares de benefícios e melhorias contínuas, a partir da concepção de técnica em Heidegger é retirado o campo aberto das múltiplas possibilidades, dando lugar ao 'destino fatalístico' providenciado pela tecnificação ou, mais precisamente, a metafísica consumada. A saída que Heidegger encontrou para o destino 'pré'determinado pela técnica 'auto'-determinada foi a salvação. Essa salvação, conforme Miranda (2002), tem origem na concepção cristã de conversão: atinge-se a conversão por um pensamento que representa o 'giro' do homem frente ao ser, ou seja, o homem se encontra de costas para o sentido do ser. Então, con-verter-se significa girar-se para ficar de frente ao ser; para ouvir o ser que fala pelo sentido da técnica. "Desde aí recordamos e avistamos mais uma vez, o sentido de copertenência entre Homem e Ser. 'Quando o ser fala a razão se cala', dizia Heidegger. De que razão ele está falando? Da razão instrumental, certamente" (MIRANDA, 2002, p.36)

A citação acima nos enseja a exata dimensão de algumas considerações críticas acerca da concepção de Heidegger sobre a técnica. O homem, na concepção de Heidegger (1997), deve voltar-se para si mesmo no intuito de encontrar a verdade (a essência) da técnica. O filósofo alemão se utilizou da idéia do divino no intuito de buscar a compreensão acerca daquilo que lhe era ontológico, qual seja, a capacidade de criar e aprimorar artefatos que the auxiliam em sua relação inextinguível com a natureza. Para tanto deve-se abdicar dessa capacidade, de adequar os meios para a obtenção de determinados fins, para que assim se possa 'desocultar' a verdadeira essência dessa própria capacidade. Mais uma vez, com o auxílio de Heidegger, caímos em um paradoxo sem solução: para que possamos retornar a essência do ser, da qual fomos afastados no decorrer histórico por meio da técnica ocidental, ou razão instrumental, devemos abdicar de nossa 
capacidade de nos relacionarmos com a natureza através da adequação de meios a fins, ou seja, por meio do desenvolvimento de tecnologia.

Possivelmente poucos autores foram tão a fundo na busca em desocultar a essência da questão da técnica em Heidegger (1997) como Álvaro Vieira Pinto em sua obra $O$ conceito de tecnologia. Destacamos aqui alguns trechos fundamentais que nos auxiliaram a desvelar no plano filosófico o horror tecnológico heideggeriano. Para Viera Pinto (2005), a ideia central de Heidegger no que tange à questão da técnica ${ }^{2}$ se resume em "supor que a essência da técnica consiste no 'desvelamento', na 'desocultação' do ser [Entbergen], aquilo que, examinando a palavra na composição etimológica, os gregos denominavam aletheia, e que assumiu o significado comum de 'verdade"' (VIEIRA PINTO, p.150). Mais adiante, o filósofo brasileiro continua o seu "desocultamento" da definição de Heidegger sobre a técnica:

Ao sabor das possibilidades que descobre como proceder a decomposições lexicológicas, Heidegger, movido pela hostilidade à técnica real, afasta a significação corrente da palavra e entra a especular sobre o segundo sentido, o erudito, o etimológico, daquele termo. A essência da técnica desliga-se assim do fazer, acepção sem dúvida plebeia, material e indigna de um metafísico, e passa a ter o significado de trazer à luz, isto é revelar, desvendar, conforme a composição original da palavra grega alétheia (VIEIRA PINTO, 2005, p. 151).

Aqui reside a radical distinção entre Heidegger e Marx: o primeiro apreende a técnica como algo existente por si, a "coisa em si", ou seja, a técnica se transforma em uma entidade dotada de autonomia histórica, sendo que, ao demonstrar sua repulsa à tecnologia e tudo o que ela representa no mundo moderno, Heidegger isola a técnica na subjetividade metafísica, retirando assim toda a materialidade contida em sua relação com a constituição do ser social.

O contraponto em que nos apoiamos para questionar a questão da técnica em Heidegger é que, sem ter assegurada a sua existência material, não seria possível ao homem entregar-se ao trabalho do pensamento, aí incluída a retórica metafísica. O ponto de partida, e aqui seguramente podemos afirmar que este era o ponto inicial de Marx no tocante a tecnologia, é identificarmos qual o papel que os conhecimentos e artefatos tecnológicos desempenham na produção da existência do homem.

\footnotetext{
${ }^{2}$ Na verdade $A$ questão da técnica é o título de uma famosa conferência em que Heidegger debruçase com grande afinco sobre as questões concernentes ao desenvolvimento tecnológico do período posterior a Segunda Guerra Mundial.
}

Cad. de Pesq. Interdisc. em Ci-s. Hum-s., Florianópolis, v.12, n.101, p.171-198, ago/dez 2011 
Heidegger, ao identificar a técnica moderna com sua utilização capitalista, contribui de maneira decisiva para o fetiche da tecnologia ao, primeiramente, "coisificar" a técnica como ente autônomo à sociedade e, consequentemente, ao desvinculá-la a todo modo de seu caráter histórico, político e econômico. O retorno à essência ou ao simples, conforme Heidegger é a negação de toda e qualquer utilização de tecnologia moderna, sem se fazer qualquer menção à utilização capitalista da mesma. Sendo assim, Heidegger fornece as condições objetivas para o desenvolvimento de uma subjetividade a-histórica e a-crítica, auxiliando de maneira indelével o que Kosik (2002) caracteriza como pseudoconcreticidade ${ }^{3}$, marcada pelas relações sociais de produção alienadas calcadas unicamente na valorização do valor.

\section{MARCUSE E O PESSIMISMO TECNOLÓGICO}

Propositalmente fizemos a análise da concepção marcuseana de tecnologia logo em seguida a de Heidegger, sendo o nosso propósito nesse item verificar: 1) em que medida se configura a influência de Martin Heidegger, do qual Marcuse foi assistente, em sua ideia de racionalidade tecnológica; e consequentemente, como tal influência determinou o seu avanço ou retrocesso em termos de apropriação do conceito de tecnologia e; 2) sendo Marcuse um marxista que por muitos anos advogou em prol da revolução ${ }^{4}$, como a relação desenvolvida entre Marx e Heidegger pode ter impossibilitado Marcuse de avançar em sua análise sobre a apropriação da ciência e da tecnologia como forças produtivas capitalistas.

Duas obras extremamente representativas do contexto na qual se encontrava a sociedade, particularmente a europeia, contribuíram sobremaneira para a concepção marcuseana de tecnologia. A primeira delas surgia como herança de seus colegas frankfurteanos, Adorno e Horkheimer (1985), intitulada A dialética do

\footnotetext{
${ }^{3}$ Pseudoconcreticidade segundo Kosik (2002, p.15) é o "complexo dos fenômenos que povoam o ambiente cotidiano e a atmosfera comum na vida humana, que, com a sua regularidade, imediatismo e evidência, penetram na consciência dos indivíduos agentes, assumindo um aspecto independente e natural".

${ }^{4} \mathrm{O}$ caráter revolucionário do pensamento de Marcuse é evidenciado em uma de suas últimas entrevistas em que se verifica a proximidade com as teses propostas por Marx sobre Feuerbach onde afirma que gostaria de ser "um filósofo num sentido hoje quase inconcebível, quer dizer, alguém que com base no que aprendeu e na sua experiência possa realmente entender, descobrir e transformar a realidade em que vive" (MARCUSE, 1999, p.11-12)
}

Cad. de Pesq. Interdisc. em Ci-s. Hum-s., Florianópolis, v.12, n.101, p.171-198, ago/dez 2011 
esclarecimento editada em 1944. A obra em questão expõe o novo e longínquo direcionamento pessimista da Teoria Crítica no período pós-guerra. Os autores destacaram, na obra, o estrondoso sucesso que o período iluminista teve em banir o mito (o divino) no desenvolvimento da moderna ciência e tecnologia, que acabou culminando, paradoxalmente, no século XX num terrível retorno ao mito na forma do fascismo e da cultura de massa.

Quando, em 1949, escreveu um de seus mais famosos textos intitulado $A$ questão da técnica - a segunda obra a influenciar Marcuse no período -, Heidegger (1997) argumentou que o mundo moderno foi determinado inteiramente pelo "espírito tecnológico" que reduz todos os seres a um mero componente em um vasto sistema de instrumentalidades. O foco central da obra heideggeriana era salientar que toda e qualquer atividade particular que era exercida com o auxílio do aparato tecnológico tornou-se uma tendência redutiva que afetava todo e qualquer aspecto da vida cotidiana. Esta era a perspectiva extremamente distópica acerca das possibilidades negativas que os artefatos e a própria sociedade tecnológica desenhavam em termos de futuro e com larga prevalência na Europa, pois a fé e a esperança na ciência e tecnologia ainda prosperava nos Estados Unidos na década de 1960. Foi em meio a esse crescente clima de incerteza e 'tecnofobia' que Marcuse (1967) lançou O homem unidimensional.

Segundo Loureiro (2005), essa obra, a mais famosa e discutida de Marcuse, sintetiza o período mais pessimista do autor, que acaba se confirmando, conforme suas próprias palavras:

Nascemos e morremos racional e produtivamente. Sabemos que a destruição é o preço do progresso, como a morte é o preço da vida, que a renúncia e a labuta são os requisitos para a satisfação e o prazer, que os negócios devem prosseguir e que as alternativas são utópicas. (MARCUSE, 1967, p.143)

Marcuse viu na sociedade industrial avançada, ou no capitalismo avançado, uma sociedade "democrática totalitária" (LOUREIRO, 2005), onde todo e qualquer tipo de oposição se encontra integrado e as minorias contrárias a esse movimento indicariam uma possível alternativa, sem qualquer garantia de sucesso. O grande empecilho, identificado por Marcuse, para uma possível transformação radical da sociedade e que já vinha se delineando em outra obra sua, Eros e Civilização, é a 
inexistência de um sujeito histórico que viabilizasse essa "utopia concreta" ${ }^{5}$, ou seja, "uma inversão no rumo do progresso" (MARCUSE, 1975, p.15). Tornou-se interessante apontarmos como na obra sua de maior abrangência, $O$ homem unidimensional, Marcuse avaliou de forma pessimista as possibilidades da tecnologia como forças produtivas na sociedade industrial avançada, sendo que o autor vinha numa curva ascendente em termos de perspectivas de superação do capital, conforme os trechos de sua obra anterior.

Conforme Feenberg e Leiss (2007), Marcuse argumentou em sua obra que a razão instrumental havia triunfado sobre a forma mais elementar de atividade humana, contida na adequação entre fins e meios. Não eram o conhecimento ou os aparatos tecnológicos em si os elementos fundamentais para tal condição, mas a relação tecnológica que se estabelecia na materialidade que tornava possível o progresso da ciência e da técnica num primeiro plano.

Assim como Heidegger afirmava que a estrutura da experiência era obscurecida pela tecnologia reveladora, Marcuse concluiu que a racionalidade tecnológica distorcia e reduzia a experiência a mero retalho empobrecido. Porém, Marcuse não tratou essa transformação como sendo um fenômeno meramente "espiritual" - conforme Heidegger aceitara -, mas, conforme Adorno e Horkheimer, como um fenômeno social baseado na perpetuação do capitalismo sob novas condições - proporcionadas pelo avanço tecnológico -, que haviam tornado a velha "realidade principal" obsoleta. Assim, a produção em massa, o consumo de massa e a cultura de massa prevaleciam sobre as formas tradicionais de consciência; e uma sociedade que "compartilhava maravilhas" absorve a classe trabalhadora agora e para todo o sempre. Conforme Loureiro (1998, p.115), para Marcuse O homem unidimensional oscila entre duas hipóteses contraditórias: "a de que a sociedade industrial avançada não permitirá qualquer ruptura e a de que há tendências capazes de fazer explodir a sociedade. Mas a primeira predomina".

A racionalidade tecnológica tem, no capitalismo, um vínculo indissociável com a dominação política, nesse caso, a ciência e a técnica estão inseridas em um projeto que serve aos interesses do capital, destarte, não são neutras. A crítica da neutralidade axiológica da ciência e da tecnologia foi alvo de uma conferência sua, feita em 1964, intitulada Industrialização e capitalismo na obra de Max Weber.

\footnotetext{
${ }^{5} \mathrm{O}$ conceito de utopia concreta é claramente influenciado por Ernst Bloch e sua grande obra $\mathrm{O}$ princípio esperança (2005) lançada em 1959.

Cad. de Pesq. Interdisc. em Ci-s. Hum-s., Florianópolis, v.12, n.101, p.171-198, ago/dez 2011
} 
Nesse texto percebe-se a retomada da crítica da economia política e dos pressupostos marxianos, indicando-se as dificuldades analíticas observadas pela racionalidade objetivada pelo capital que impedem o desenvolvimento de qualquer esquema que demonstre a contradição entre as forças produtivas e relações de produção. A grande contribuição desse texto talvez seja a crítica incisiva a Max Weber no que se refere à distinção entre desenvolvimento das forças produtivas, via racionalidade científico-tecnológica (como característica ontológica e indissociável do homem como ser social) e desenvolvimento das forças produtivas sob o domínio do capital, polemizando diretamente com Jürgen Habermas que adotou a concepção weberiana em sua obra Técnica e ciência como ideologia (1968).

Marcuse exorcizou os últimos resquícios de sua aproximação com Heidegger ao apontar em Weber o mesmo problema em que o primeiro igualmente incidiu: a industrialização e o capitalismo, segundo Weber, seriam o destino histórico do Ocidente, assim como a racionalidade técnica seria o destino fatídico da sociedade moderna para Heidegger. Segundo Marcuse, a teoria da neutralidade axiológica interna da ciência, desenvolvida por Weber, acabou sendo o que se constatou na prática: "a tentativa de tornar a ciência livre para a aceitação de valores vinculantes impostos a partir de seu exterior" (MARCUSE, 2006, p.01).

Ao abdicar do fundamento ontológico contido na racionalidade formal, Weber encerrou a mesma em um fundamento funcional: a racionalidade humana se torna instrumental em prol da racionalização capitalista de perpetuação contínua de valorização do valor. A crítica proferida por Marcuse às considerações de Weber indica que na própria realização (objetivação) da racionalidade capitalista, as suas características já foram superadas, consequentemente a razão instrumental capitalista acaba paradoxalmente se constituindo em uma irracionalidade.

No desenvolvimento da racionalidade capitalista a irracionalidade se torna
razão: razão enquanto desenvolvimento frenético das forças produtivas,
conquista da natureza, ampliação da riqueza de mercadorias [...]; mas
irracional porque a produtividade superior, a dominação da natureza e a
riqueza social se tornam forças destrutivas, destrutivas não só no sentido
figurado, na liquidação dos chamados valores superiores, mas em sentido
literal: a luta pela existência se aguça tanto no plano interno dos Estados
nacionais como no plano internacional, e a agressão represada se
descarrega na legitimação de crueldades medievais (a tortura) e no
genocídio promovido cientificamente (MARCUSE, 2006, p.5).

Nesse caso, a própria racionalidade técnica acaba se tornando um aparato ideológico do capital, o que Marcuse habilmente identifica: 
A técnica é sempre um projeto sócio-histórico; nela encontram-se projetado o que uma sociedade e os interesses nela dominantes pretendem fazer com o homem e com as coisas. Uma tal "finalidade" da dominação é "material", e nesta medida pertence à própria forma da razão técnica (MARCUSE, 2006, p.15).

Verificamos em nossa análise da concepção de tecnologia compreendida por Marcuse que, evidentemente, não há como desvincular historicamente o autor de sua obra. Sendo assim, a partir do momento em que Marcuse se deixou consumir pelo zeitgeist do pós-guerra, foi tomado por uma perspectiva extremamente pessimista que acabou perpassando seus escritos acerca da sociedade tecnológica, o que é verificado com maior visibilidade em sua obra $\mathrm{O}$ homem unidimensional. $\mathrm{Na}$ verdade, o "desencanto pelo mundo" - encarnado na falta de perspectiva em qualquer possibilidade de alteração no modus operandi da "sociedade industrial avançada" e na completa imobilização da "classe revolucionária por excelência" tornou-se uma 'herança maldita'.

Mesmo que em seus últimos anos de vida, Marcuse tenha prescindido da prática - ao se afastar das discussões políticas e ter adotado a sublimação artística em sua dimensão estética como a "negação da realidade"6 (MÉSZARÓS, 2004, p.207), como sendo a fonte de inspiração às suas aspirações utópicas transcendentais de transformação do mundo -, o filósofo alemão esteve sempre muito mais próximo de Marx do que grande parte dos membros da Escola de Frankfurt, particularmente comparado a Adorno, com quem rompeu em 1969 em virtude de seu apoio irrestrito à livre manifestação dos estudantes em relação à postura do Instituto de Pesquisa Social (lar dos frankfurteanos) do qual este último era o reitor?

\footnotetext{
${ }^{6}$ Para além da adoção da estética como campo preferencial de seus escritos, Mészarós (2004) identifica em Marcuse uma possível guinada elitista quando o mesmo afirma que o artista (escritor), "é obrigado a tomar posição contra o povo: ele não pode falar sua língua. Nesse sentido, o conceito de elite tem atualmente um significado radical' (MARCUSE apud MÉSZARÓS, 2004, p.208).

${ }^{7}$ Conforme verificado nas cartas trocadas por ambos no período citado no texto. Para leitura das cartas ver ANTIVALOR. Cartas de Adorno e Marcuse. Tradução de Isabel Maria Loureiro. Disponível em: <http://antivalor2.vilabol.uol.com.br/textos/frankfurt/adorno/adorno_23.html>. Acesso em: 18 de maio de 2007.

Cad. de Pesq. Interdisc. em Ci-s. Hum-s., Florianópolis, v.12, n.101, p.171-198, ago/dez 2011
} 


\section{HABERMAS E A ‘REDUÇÃO’ TECNOLÓGICA}

No que se refere à concepção de Habermas acerca da tecnologia, utilizamos como obra principal Técnica e ciência como ideologia, publicada em 1968. A nosso ver, a obra em si se caracteriza por duas questões fundamentais, as quais são tratadas em termos analíticos individualmente, mas que em sua totalidade se autocomplementam: 1) a obra foi desenvolvida em torno da crítica à Marcuse e à sua compreensão acerca da utilização da ciência e da tecnologia como forma de dominação, vinculada particularmente à sua obra $O$ homem unidimensional, utilizando como pressuposto teórico para tal crítica a abordagem de Max Weber sobre a racionalidade instrumental e; 2) a refutação a Marx a partir da suposta superação da teoria do valor-trabalho utilizando como pressuposto teórico para tal os elementos, ainda em sua proto-forma, de sua 'teoria do agir comunicativo'.

No entender de Habermas, Marcuse compreendeu que a racionalidade técnico-científica orientada pela consecução de meios e fins tem como pressuposto a dominação do homem e da natureza. Sendo assim, a racionalidade inerente ao desenvolvimento tecnológico é pensada como ideologia para a auto-perpetuação do sistema, visão essa que tem sua origem em uma percepção pessimista e negativa da realidade em função da materialidade concreta vivenciada por Marcuse. Segundo Organista (2006, p.107), o que Habermas concluiu foi que Marcuse realizou "a fusão de técnica e dominação, em que se oculta, por trás de uma aparente neutralidade, um projeto, diga-se de passagem, eficiente, de um modo afeito aos interesses das classes dominantes". A crítica proferida à Marcuse se concretizou a partir do momento em que este propôs como contraponto a tal desenvolvimento, a criação de uma nova ciência e tecnologia no intuito de buscar a emancipação humana. Habermas se colocou enfaticamente contra a constituição de uma nova ciência e tecnologia emancipadora ao afirmar que:

Assim como não é admissível a ideia de uma nova técnica, também não pode pensar-se de um modo consequente a ideia de uma nova ciência, já que, no nosso contexto, ciência deve significar sempre a ciência moderna, uma ciência obrigada a manter atitude de uma possível disposição técnica: tal como para a sua função, assim também para o progresso científicotécnico em geral, não existe substituto algum que seria "mais humano" (HABERMAS, 2001, p.53). 
Em favor de uma tecnocracia pragmatista de cunho essencialmente instrumentalista, Habermas apud Mészarós (2004, p.202) afirmou de maneira veemente que:

\begin{abstract}
Arnold Gehlen observou, de um modo que me parece conclusivo, que há uma conexão imanente entre a tecnologia por nós conhecida e a estrutura da ação intencional-racional. Se compreendermos o sistema comportamental da ação regulada por seus próprios resultados como a conjunção da decisão racional e da ação instrumental, poderemos reconstruir a história da tecnologia do ponto de vista da objetivação passoa-passo dos elementos daquele próprio sistema, [...] Desse modo, o desenvolvimento tecnológico segue uma lógica que corresponde à estrutura da ação intencional-racional regulada por seus próprios resultados, que é de fato a estrutura do trabalho. Compreendendo isto, é impossível imaginar - enquanto a organização da natureza humana não mudar e, portanto, enquanto tivermos de conseguir a autopreservação pelo trabalho social e com o auxílio dos meios que substituem o trabalho - como poderíamos renunciar [...] a nossa tecnologia em favor de outra qualitativamente diferente.
\end{abstract}

Ao equiparar a tecnologia vigente ("a nossa tecnologia") à própria organização da natureza humana, Habermas duplamente reforçou a impossibilidade de suplantar o status quo do capital: ao reduzir a tecnologia concebida a partir da lógica do capital, sendo esta como inerente à própria natureza humana; e, como consequência direta, ao eternizar as relações sociais capitalistas naturalizando-as.

Para Habermas, uma consciência tecnocrática bem sucedida se reproduz pela sua própria dinâmica ao submeter a sua capacidade de realizar e produzir à ambição de ampliar para todas as esferas da ação humana a sua ação racional teleológica, qual seja, uma racionalidade que se assenta nos pressupostos relacionais meio e fim. Porém, a garantia de que ela siga com esperado grau de eficiência e de regras técnicas específicas só é possível mediante a sua institucionalização via Estado, conforme Weber, que via em tal apropriação a manifestação concreta da racionalização.

Ao confrontar a crítica de Marcuse ao aparato tecnocrático estatal como uma tendência para a administração total na sociedade industrial avançada, com base em uma possível superação da análise weberiana, Habermas se aproveitou também de um contexto histórico favorável, pois conforme Feenberg (2007, p.2) "este contexto foi a retirada das esperanças utópicas nas décadas de 1970 e 1980, uma espécie de neue Sachlichkeit, ou 'nova sobriedade'”. Torna-se interessante mencionar que Habermas se utilizou da racionalidade positivizada como crítica a análise utópica de Marcuse frente à possibilidade de uma tecnologia reorientada para valores não-capitalistas.

Cad. de Pesq. Interdisc. em Ci-s. Hum-s., Florianópolis, v.12, n.101, p.171-198, ago/dez 2011 
A vinculação direta à matriz weberiana não se limita à superação da análise de Weber quanto aos perigos de racionalização instrumental via burocracia tecnocrática, ou conforme o próprio Weber "a gaiola de aço", por meio do agir comunicativo, pois conforme Mészarós (2004, p.219) "a influência de Talcott Parsons como mediador de Weber para os europeus, a partir de uma perspectiva caracteristicamente norte-americana" se verifica em Habermas por suas menções feitas a teoria da ação do referido autor americano na obra Técnica e ciência como ideologia. O pragmatismo inerente ao próprio modus operandi das organizações capitalistas, reforçado pela sua perspectiva eternizante do modo de produção capitalista e validado por Weber, é verificado também por Tragtenberg (1985, p.212) ao afirmar que:

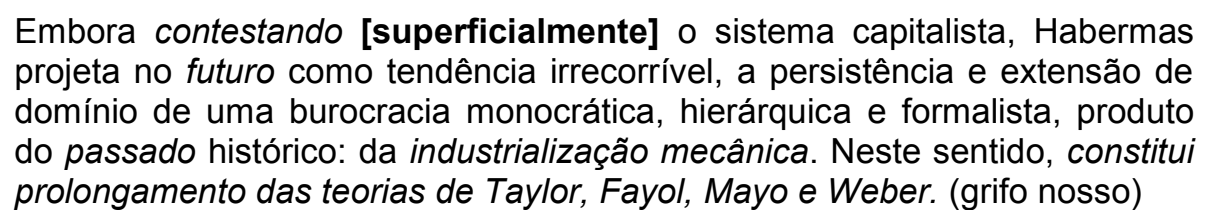

Trataremos a partir daqui da segunda questão evidenciada na obra Técnica e ciência como ideologia, qual seja, como Habermas refuta Marx a partir da suposta superação de sua teoria do valor-trabalho, utilizando como pressuposto teórico, para tanto, as categorias essenciais de sua teoria do agir comunicativo. Para adentrarmos em tal análise tornou-se necessário retornarmos à objetividade histórica para compreendermos como esta determina a subjetividade ideológica, mesmo quando Habermas (2001) propõe o "desuso" de duas categorias fundamentais de Marx, a saber, a luta de classes e a ideologia. A refutação a Marx tem seus primeiros contornos centrados na figura de um dos maiores marxistas do século XX: Georg Lukács. Conforme Nogueira (2008), o embate de Habermas com Lukács tem seu primeiro registro em um texto escrito pelo primeiro intitulado Trabalho e interação: notas sobre a filosofia hegeliana do período de Jena, publicado em 1967, onde o mesmo teve por objetivo glosar os textos filosóficos onde Hegel desenvolveu seu pensamento acerca da filosofia do espírito. Em concordância com algumas investigações marxistas que verificam que tais estudos de Hegel estavam sob a influência dos textos dos economistas clássicos e que seu objetivo era a compreensão da sociedade capitalista alemã da época, Habermas, porém, divergiu quanto ao aprofundamento de tais análises por parte dos marxistas, em especial, de Georg Lukács e particularmente de sua obra O jovem Hegel, publicada em 1938. 
A divergência se deu a partir da perspectiva hegeliana levada a cabo por ambos os autores: para Lukács o trabalho tinha valor fundamental no que se refere à tematização do mundo presente e na objetivação do espírito subjetivo; Habermas criticou Lukács pela posição central que a categoria trabalho ocupou em sua análise sobre Hegel, onde Habermas propôs a desvinculação entre trabalho e interação. Lukács recuperou os textos de juventude de Hegel no intuito de demonstrar o vínculo existente entre este e a tradição iluminista alemã, apontando o caráter inovador da filosofia hegeliana. Segundo Nogueira (2008, p.3):

\begin{abstract}
A inovação se dá na busca realizada por Hegel das conformações objetivas em que a razão, o espírito absoluto, encarna-se como resolução das contradições subjetivas anteriormente existentes. [...] Hegel inaugura, portanto, na história da Filosofia, uma compreensão histórica das conexões entre o pensar e o ser que, de forma indissociável, se articulam e se engendram. $O$ trabalho, nesse aspecto, é a atividade que responderá pelo ser do homem no mundo e que revelará o caráter interativo da racionalidade humana, como também o seu caráter resolutivo posto que o homem é um ser que trabalha, que manifesta racionalidade no trabalho e conforma o mundo conforme os ditames da razão.
\end{abstract}

A partir da análise de Lukács, Hegel rompera com a perspectiva especulativa do idealismo subjetivo e centrara no mundo presente a sua perspectiva ante o homem e a racionalidade.

É na dialética hegeliana do trabalho, posta em movimento quando o homem confecciona instrumentos visando a diminuição significativa de seu esforço, que Lukács, em sintonia com Marx, postulará os veios progressistas de Hegel e antecipação da tematização marxiana da centralidade do trabalho (NOGUEIRA, 2008, p. 03).

Habermas reconheceu em parte a importância do papel do trabalho na interrelação entre homem e natureza, porém redimensionou a ênfase dada por Lukács ao retirar dos textos de Hegel três momentos em que o homem se comunica com outros homens: família, trabalho e linguagem. No que se refere à linguagem, esta seria a expressão da consciência que sintetiza a razão comunicativa por permitir a elaboração de estratégias interativas entre os homens. A fala, por atribuir nomes as coisas e tratar dos objetos como distintos da consciência, promove a diferenciação entre ser e consciência, assim como, permite que os homens possam interagir. Portanto, conforme Nogueira (2008, p.4) "a linguagem é sublinhada por Habermas como a atividade que veicula e suporta a distinção do homem e sua humanização".

Habermas afirmou categoricamente a perda da centralidade da teoria do valor-trabalho marxiana em detrimento a ciência e a técnica, posto que estas agora ocupavam a primazia da base valorativa da sociedade industrial avançada. 
Com a investigação industrial de grande estilo, a ciência, a técnica e a revalorização do capital confluem num único sistema. [...] Deste modo, a ciência e a técnica transformam-se na primeira força produtiva e caem assim as condições e aplicação da teoria marxiana do valor-trabalho. Já não mais tem sentido computar os contributos ao capital para investimentos na investigação e no desenvolvimento sobre a base do valor da força de trabalho não qualificada (simples), se o progresso técnico e científico se tornou uma fonte independente de mais-valia frente à fonte de mais-valia que é a única tomada em consideração por Marx: a força de trabalho dos produtores imediatos tem cada vez menos importância (HABERMAS, 2001, p.72-73).

Por meio da autonomização da ciência - que a partir de então definia o progresso técnico - Habermas contribuiu de maneira indelével para o fetiche da tecnologia, o que funciona como um contributo ideológico para a perpetuação da valorização do valor. "Como variável independente, aparece então um progresso quase autônomo da ciência e da técnica, do qual depende de fato a outra variável mais importante do sistema, a saber, o crescimento econômico" (HABERMAS, 2001, p.73). Nesse caso, todo o desenvolvimento econômico passa a ser determinado pela lógica da "cientificação da técnica".

Reduzindo a posição central do trabalho no organismo sócio-metabólico do capital em prol da autodeterminação da ciência e tecnologia, Habermas excluiu por completo toda e qualquer forma de contradição existente na relação entre trabalho vivo, ciência e tecnologia, repondo em seu lugar a busca do consenso e da harmonia.

Conforme Mészarós (2004), o nexo lógico da concepção habermasiana em buscar o consenso depende da eliminação das antigas contradições do século XIX, tais como as lutas de classe e a ideologia, como também as futuras contradições oriundas do acirramento da relação entre as forças produtivas e as relações de produção. Tais relações que têm na exploração a sua característica essencial são abrandadas através da busca do consenso, sendo que na sociedade industrial avançada os interesses da classe trabalhadora, segundo Habermas, estão em plena convergência com os interesses do capital através de um capitalismo regulamentado pelo Estado.

\footnotetext{
O capitalismo estatalmente regulado, que surgiu de uma reação contra as ameaças aos sistemas geradas pelo antagonismo aberto das classes, pacifica o conflito das classes. O sistema do capitalismo tardio está a tal ponto determinado por uma política de compensações que assegura a lealdade das massas dependentes do trabalho, ou seja, por uma política de evitação do conflito. (HABERMAS, 2001, p.76)
} 
Certamente, Habermas, ao se referir às "políticas de compensação" inerentes a uma "política de evitação de conflito", só podia estar falando do alto do lócus historicamente central de seu debate, qual seja, os países desenvolvidos da Europa e os Estados Unidos, onde as referidas políticas compensatórias podem ser traduzidas como o Estado de Bem Estar Social (Walfare State). Nesse caso, a grande parcela da população trabalhadora mundial fica excluída de sua formulação acerca da não-centralidade do trabalho, onde o exército industrial de reserva providenciado pela mão de obra barata residente nos países "em desenvolvimento" ou "do Terceiro Mundo" é menosprezada, e excluída de qualquer relação possível existente entre a produção ad eternum de valor e a exploração da força de trabalho.

Os grupos subprivilegiados não são classes sociais. Também nunca representam potencialmente a massa da população. A sua privação de direitos e a sua pauperização já não coincide com a exploração, porque o sistema não vive do seu trabalho. Em todo o caso, podem representar uma fase passada da exploração (HABERMAS, 2001, p.79).

Ao afirmar que os grupos subprivilegiados ${ }^{8}$ não representam a massa da população e que não sofrem a exploração capitalista, Habermas demonstrou a característica principal de seu discurso: o eurocentrismo desmedido, que compromete toda a estrutura teórica de sua obra no que tange ao seu caráter totalitário e universalizante. Essa afirmação é confirmada pelo próprio Habermas que em uma entrevista dada a Perry Anderson e Peter Dews, quando ambos fazem o seguinte questionamento ao filósofo alemão:

\begin{abstract}
A tradição da Escola de Frankfurt como um todo concentrou sua análise nas sociedades capitalistas mais avançadas, à custa de qualquer consideração do capitalismo como um sistema global. Em sua opinião, as concepções de socialismo desenvolvidas no decorrer das lutas antiimperialistas e anticapitalistas no Terceiro Mundo têm algum significado para as tarefas do socialismo democrático no mundo capitalista avançado? Reciprocamente, sua própria análise do capitalismo avançado tem alguma lição para as forças socialistas do Terceiro Mundo? (ANDERSON; DEWS apud MÉSZARÓS, 2004, p.79)
\end{abstract}

Eis que Habermas se limitou a responder a tal questão de fundamental importância da seguinte forma: "Estou tentado a responder 'não' para ambos os casos. Tenho consciência de que esta é uma visão eurocêntrica, limitada. Eu preferiria não responder a esta pergunta" (HABERMAS apud MÉSZARÓS, 2004, p.79).

\footnotetext{
${ }^{8}$ Conforme Organista (2006) compreendem os grupos que ficaram à margem do sistema capitalista avançado como movimentos femininos, de etnia, estudantes etc. Para fins analíticos e como forma de reforçar a perspectiva crítica com base em Marx, consideramos os grupos subprivilegiados como 'excluídos economicamente'.
}

Cad. de Pesq. Interdisc. em Ci-s. Hum-s., Florianópolis, v.12, n.101, p.171-198, ago/dez 2011 
A partir de tal afirmação concedida por Habermas, estamos tentados a minimizar os impactos da abordagem habermasiana que questiona o caráter ideológico contido na apropriação da ciência e da tecnologia por parte do sistema sócio-metabólico do capital, o que foi acertadamente demonstrado por Marcuse; ao que sua abordagem teleologicamente orientada por uma tecnoburocracia só podia ficar circunscrita aos limites de mera apologia ao modo de produção capitalista e fatalmente propositora da eternização das relações sociais alienadas pelo sistema sócio-metabólico do capital.

\section{VIEIRA PINTO E A ONTOLOGIA TECNOLÓGICA}

O presente item pretende analisar a contribuição significativa de Álvaro Vieira Pinto para o debate atual sobre a produção do conhecimento científico-tecnológico, tendo por referencial teórico seus diversos escritos, fundamentalmente a vasta obra O conceito de tecnologia (2005).

Tendo por base a concepção dialética da realidade e, nela, a relação entre a totalidade histórica e o indivíduo como ser social, não há como desvincular a trajetória da vida de Vieira Pinto de sua produção científica. Assim, o produto dessa relação, no caso, os seus escritos, desenvolveu-se inicialmente a partir do existencialismo heideggeriano, que foi sendo progressivamente criticado a ponto de ser refutado por completo na obra supracitada. A superação realizada por Vieira Pinto e evidenciada na obra $O$ conceito de tecnologia deve-se sobremaneira à sua apropriação teórico-metodológica das obras de Marx, Engels e, em uma parcela menor, de Lukács 9 .

Ressaltamos, em um primeiro momento, a crítica direta de Vieira Pinto a Heidegger, o que se dá principalmente pelo aprofundamento de suas leituras de Marx e de Engels, que têm início já na década de 1960. Como consequência, qualquer noção de caráter existencialista é superada no debate do autor mediante a compreensão materialista histórica marxiana em que a categoria trabalho ganha novos contornos analíticos (verificáveis na obra em questão, finalizada em 1974). A

\footnotetext{
9 Para maiores detalhes biográficos acerca de Vieira Pinto, recomendamos a leitura do artigo de Freitas (2006)Economia e educação: a contribuição de Álvaro Vieira Pinto para o estudo histórico da tecnologia.

Cad. de Pesq. Interdisc. em Ci-s. Hum-s., Florianópolis, v.12, n.101, p.171-198, ago/dez 2011
} 
obra O conceito de tecnologia evidencia, como um todo, a superação teóricometodológica que implica a compreensão dialética da realidade, envolvendo inclusive o reconhecimento da ontologia do ser social na totalidade histórica e, em particular, na categoria tecnologia.

Unicamente a concepção dialética pode apreender a essência da técnica,
quando a revela na formação contraditória de fruto e origem da razão. [...] A
dialética ensina-nos a ver a unidade do pensamento e do fato, do método e
da máquina, do trabalho intelectual e do físico (VIEIRA PINTO, 2005,
p.362).

Alguns autores (FREITAS, 2006; DIAS; ARAÚJO, 2002; TOLEDO, 2005) situam Álvaro Vieira Pinto como o representante de um zeitgeist, principalmente na época em que esteve presente no Instituto Social de Estudos Brasileiros (ISEB) e que era um dos precursores do desenvolvimentismo. Destacamos, porém, que Vieira Pinto e sua obra derradeira suplantam o período histórico de constituição desta última. Ressaltamos, também, que grande parte das críticas feitas por Vieira Pinto acerca do debate sobre a apropriação e utilização social da tecnologia não foram apreendidas por muitos pensadores atuais, mesmo por muitos daqueles que se colocam no campo da esquerda e, indubitavelmente, pelos ideólogos do capital. Daí o pensamento expresso na obra O conceito de tecnologia ser tão necessário hoje quanto o foi à época da sua elaboração.

Vieira Pinto desenvolveu sua análise conceitual a partir dos extremos que perpassavam o debate sobre a tecnologia, dirigindo críticas tanto aos defensores, que se "maravilhavam" com as possibilidades da mesma, quanto aos "tecnofóbicos", que alardeavam os perigos que circundavam a utilização dos artefatos tecnológicos. A crítica principal dizia respeito ao fato de que tanto esses quanto aqueles não apreendiam a totalidade histórica inerente à questão da tecnologia: a) os primeiros (os defensores), por desconsiderarem as consequências da apropriação tecnológica por parte do capital, apregoando uma possível "neutralidade tecno-científica", e b) os segundos (os tecnofóbicos), por imporem uma 'essência maligna' à tecnologia - ou conforme Guimarães (1995), um "determinismo tecnológico" - onde todos os males provenientes das guerras e da utilização negativa da aplicação tecnológica da ciência, ou conforme Mészaros (2002), a produção destrutiva, se dão em decorrência da tecnologia em si.

Os dois extremos impõem uma (pretensa) teleologia à história, sendo que a consequência de tal apropriação a-histórica implica mais propriamente em um 
fetiche tecnológico (NOVAES, 2007; FEENBERG, 2002), desconsiderando por completo a relação ontológica existente entre o desenvolvimento do homem enquanto ser social e o trabalho enquanto elemento fundamental para esse salto qualitativo.

\begin{abstract}
Pela ação dos homens, a realidade se vai povoando de produtos de fabricação intensional, realizada pelo ser que se tornou projetante. A possibilidade de tal ação depende da capacidade abstrativa, que conduz a criar a imagem reflexa das propriedades dos corpos e fenômenos objetivos, e do poder de ligar uma imagem a outra, dando lugar a uma terceira (VIEIRA PINTO, 2005, p.55).
\end{abstract}

Tal determinismo é proveniente, em grande parte, da apropriação ideológica de certos autores que atribuem o desenvolvimento tecnológico ao desenvolvimento das forças produtivas capitalistas, quando não fundem ambos em um só corpo, conforme explicitado por Lukács (1989).Ambos os extremos são problemáticos para Vieira Pinto, pois escondem a (real) essência da tecnologia: a de ser instrumento fundamental de potencialização da relação homem-natureza. Além disso, os extremos contribuem para o processo de ideologização da tecnologia, que se materializa pelo "maravilhar" do homem ante o produto de seu próprio trabalho.

O homem maravilha-se diante do que é produto seu porque, em virtude do distanciamento do mundo, causado pela perda habitual da prática da transformação material da realidade, e da impossibilidade de usar os resultados do trabalho executado, perdeu a noção de ser o autor de suas obras, as quais por isso lhe parecem estranhas (VIEIRA PINTO, 2005, p.35).

O processo de ideologização da tecnologia é melhor compreendido mediante o desenvolvimento da análise da categoria de alienação (de Marx), a partir da qual podemos considerar que o trabalhador, por meio das relações sociais capitalistas alienadas, não reconhece o produto do seu trabalho nas mercadorias devido à não propriedade dos meios de produção, objetivando o distanciamento entre o trabalhador e o produto de sua atividade laboral. Desse modo, a tecnologia serviria ao propósito do capital globalizado, na medida em que reforçaria a divisão entre trabalho manual e intelectual, implicando, inclusive, a divisão entre países periféricos e países amplamente industrializados (centrais ao capital).

\footnotetext{
Temos de denunciar o lado secreto, maligno do endeusamento da tecnologia, aquele que visa unicamente a fortalecer ideologicamente os interesses dos criadores do saber atual, a fim de conservá-lo no papel de instrumento de domínio e espoliação econômica da maior parte da humanidade, levada a trabalhar para as camadas altas dos povos senhoriais sob a falsa e emoliente impressão de estar participando, na única forma em que lhe é possível, da promoção do progresso de nosso tempo (ibidem, p.45).
} 
Torna-se providencial, nesse caso, que se impute à tecnologia um caráter fetichista, porquanto necessário para o modo de produção capitalista, que se utiliza dessa categorização como instrumento ideológico de manipulação da sociedade. "Em tal caso converte em ideologia a valoração, a exaltação do presente, procedimento muito favorável às classes sociais que desfrutam da posse dos instrumentos, bens e objetos de conforto e divertimento que a ciência do tempo lhes põe ao dispor" (ibidem, p.39).

A questão da divisão acentuada pelo capital globalizado entre países periféricos e tecnologicamente desenvolvidos foi um dos pontos centrais da crítica de Vieira Pinto, tema que perpassa sua obra e que transcende a questão da mera apropriação de tecnologia por parte dos países em desenvolvimento. O real intento do autor é revelar a dependência não somente econômica de tais povos, mas também uma dependência intelectual, fator que influencia diretamente a produção do conhecimento em tais países. O autor não poupou sua verve para demonstrar, no decorrer da obra, as consequências de se "importar" um discurso tipicamente eurocêntrico, calcado em uma materialidade inversa à realidade vivenciada nos países subdesenvolvidos tecnologicamente:

\begin{abstract}
O trabalhador das áreas pobres, sem acesso aos bens de conforto, vê com desolação a verdadeira natureza e se envergonha por viver em contato com ela, porque é induzido a julgar "natureza" o que representa apenas um produto ideológico da percepção do mundo pelos grupos sociais afortunados das regiões industrializadas presentemente dominantes (VIEIRA PINTO, 2005, p.37, grifo nosso)
\end{abstract}

O combate a essa apropriação intelectual alienada e alienante e o incentivo ao desenvolvimento científico e tecnológico nos países periféricos foi um tópico central nos escritos de Vieira Pinto. Por isso, verifica-se a crítica feita pelo autor aos mais diversos filósofos, economistas, escritores e sociólogos dos países desenvolvidos, dentre eles: Martin Heidegger, Oswald Spengler, John K. Galbraith e indiretamente aos pensadores da Escola de Frankfurt. Para Vieira Pinto, tais autores reforçam em seus escritos a relação de dependência em que deveriam permanecer os países subdesenvolvidos, contribuindo para a "exaltação do presente" providencial para a continuidade da valorização do valor conforme a necessidade da contemporânea sociabilidade do capital.

Em termos metodológicos, para Vieira Pinto era fundamental - para demonstrar sua concepção acerca da tecnologia - que primeiramente se 
"desmistificassem" os conceitos vigentes que eram reforçados por diversos autores, especialmente a noção hegemônica de "sociedade tecnológica", (que era) tratada como elemento de caráter puramente ideológico. $\mathrm{Na}$ concepção materialista histórica de Vieira Pinto (2005, p.69), "toda época é por definição única e possui a tecnologia a que pode ter acesso", ou seja, não existe "a sociedade tecnológica" auto consagrada por seus avanços indescritíveis frente à história da humanidade, mas o desenvolvimento tecnológico histórico em si. Nenhuma sociedade, independente de sua maior ou menor apropriação e produção de artefatos tecnológicos, pode ser considerada como a única sociedade tecnológica.

O filósofo brasileiro apontou as contradições e o mascaramento das relações capitalistas que perpassam a constituição da tecno-estrutura, caracterizada pelo deslocamento do poder que passa, a partir daquele período histórico (1968), das mãos dos capitalistas para as de uma classe de trabalhadores com conhecimentos e experiências técnicas diversas e "com outros talentos que a tecnologia moderna e o planejamento industrial exigem" (idem, p.440). Vieira Pinto analisou a tecnoestrutura de Galbraith como mais uma forma de acobertar a exploração da classe trabalhadora, principalmente dos países ditos em desenvolvimento, por meio de um discurso distante de qualquer criticidade e concreticidade, elencando "os técnicos" como sendo a nova classe representante do propagado deslocamento de poder e do capital humanizado. Essa afirmação é rechaçada pelo autor ao afirmar que:

Esses grupos [capitalistas], por necessidade agora tornada imperiosa em
face da realidade política do esclarecimento da consciência dos povos
explorados, propositalmente montam o artifício destinado a fazer o poder
aparecer falsamente em outro lugar, nas mãos de outras pessoas,
chamados pomposamente de "técnicos". Confecciona-se assim uma
pseudocategoria ou subclasse social, os especialistas em qualquer coisa,
que muito se envaidecem, com essa classificação, dia a dia mais
abrilhantada e valorizada, e por isso são os primeiros a sucumbir à louvação
e a propagarem-na com fervor, enquanto os nossos velhos conhecidos de
sempre, os proprietários do capital maciço ou parcelado, mas solidários,
continuam a gozar dos privilégios do verdadeiro domínio, atualmente,
segundo julgam, ainda mais agradável porque a salvo da odiosidade
popular (VIEIRA PINTO, 2005, p. 441)

O mesmo combate férreo contra autores que, mesmo se colocando "à esquerda" - por meio da crítica ao status quo capitalista - e àqueles que explicitamente fazem apologia direta ao desenvolvimento tecnológico proporcionado única e exclusivamente pelo desenvolvimento do capital, nos últimos dois séculos, é feito por Lukács (1968) e Mészáros, o qual faz a seguinte advertência: 
A afirmação de que nossa "sociedade tecnológica" é um "tipo totalmente novo de sociedade" em que "a ciência e a tecnologia ditam" o que acontece ao corpo social, abalando por sua própria conta as instituições estabelecidas e "destruindo os fundamentos sociais dos valores mais prezados”, é uma completa mistificação (MÉSZÁROS, 2004, p. 265).

Tanto para Vieira Pinto como para Mészáros é imprescindível a crítica às falsas concepções acerca da tecnologia, principalmente àquelas que impingem à tecnologia um desenvolvimento autônomo à sociedade, desligando-se totalmente, dessa forma, do próprio desenvolvimento do homem como ser social e que necessita criar racionalmente instrumentos para produzir a sua própria existência, distinguindo-se dos outros animais por meio de sua relação com a natureza.

Da mesma forma como Lukács (1968) em seu ensaio Tecnologia e relações sociais, de 1923, teceu críticas à apropriação determinista de Bukhárin frente o papel da tecnologia no desenvolvimento da sociedade, Vieira Pinto se utilizou de idêntica base epistemológica como ponto de partida para desenvolver o conceito de tecnologia: os princípios ontológicos fundamentais de Marx, tendo o trabalho como estatuto fundante. Ao romper com o idealismo metafísico, Vieira Pinto desenvolveu sua percepção analítica da questão acerca da tecnologia com base no materialismo dialético, quando a análise das contradições sociais presentes no modo de produção capitalista torna-se imprescindível para a verificação do fetichismo que perpassa o conceito de tecnologia há, pelo menos, quatro décadas. A necessária apreensão da realidade por meio do trabalho racionalmente orientado a um determinado fim e a produção dos instrumentos, sejam físicos ou mentais, como uma técnica, por exemplo, é o elemento potencializador do desenvolvimento científico e tecnológico. "A ciência ao avançar, vai deixando pelo caminho as técnicas a que dá origem, as quais, por sua vez, adquirem vida própria, constituem um plano definido do conhecimento" (VIEIRA PINTO, 2005, p.314).

O desenvolvimento do conjunto de técnicas historicamente aprimoradas pode ser verificado no modo de como o homem se relaciona dialeticamente com a natureza, no intuito de produzir a sua existência a partir do modo de produção capitalista caracterizado pela dominação do homem sobre o homem, nesse caso, a crítica que Vieira Pinto desenvolveu, tendo por base a exploração dos países "periféricos" pelos países "desenvolvidos". Na verdade, é uma crítica direta, de origem marxiana, ao modo de produção capitalista e do modo como esse se apropria da ciência e da tecnologia como forças produtivas necessárias ao processo 
de valorização do valor. A força motriz dos desenvolvimentos historicamente materializados dos últimos dois séculos foi, conforme Mészáros, de ordem socioeconômica e não científico-tecnológica, sendo essa última matriz ideológica presente no discurso dos apologetas do capital.

A ciência e a tecnologia seriam inevitavelmente absorvidas pelo processo
de articulação material alienada da lógica perversa do capital. Aliás, as
estruturas produtivas e os complexos tecnológico-instrumentais criados com
a participação ativa da ciência, sobre a base das determinações
socioeconômicas capitalistas, adquiriram um caráter que estava
harmonizado com a lógica interna do capital e lhe dava sustentação. Em
consequência, a ciência contribuiu muito para o rápido desenvolvimento
tanto da potencialidade positiva, como da destrutiva, desta formação social
(MÉSZÁROS, 2004, p.269).

Vem à tona, novamente, a partir da afirmação de Mészáros, a questão amplamente discutida por Vieira Pinto acerca da suposta "neutralidade" científica e tecnológica: não foi a partir de sua própria lógica imanente que se deu o desenvolvimento da ciência e da tecnologia e muito menos a partir do conjunto de atos individualizados de cientistas e engenheiros. A produção de valores de uso subordinada aos imperativos do valor de troca é que determinou a produção e a expansão em larga escala de mercadorias que, em sua própria constituição, materializaram o "acesso" à ciência e à tecnologia para um contingente social específico, onde a universalização dos valores de uso mostrou-se uma impossibilidade ontológica.

\section{CONSIDERAÇÕES FINAIS}

Nesse estudo abordamos as diversas perspectivas acerca da categoria tecnologia tendo por base a relação entre Heidegger, Marcuse, Habermas e Vieira Pinto, oriundas de múltiplas determinações historicamente desenvolvidas. O nosso intuito foi desvelar - à luz da materialidade dialética - algumas abordagens que exerceram e ainda exercem influência em grande parte dos enfoques sobre tecnologia e seus interlocutores. Tendo em vista o amplo espectro que permeia a tecnologia e seus aspectos filosóficos, econômicos e sociais, tornou-se necessária a análise no âmbito ideológico que se mostra campo de disputa primordial pelo fato de tanto as vertentes pessimistas quanto as otimistas acerca da tecnologia não buscarem compreendê-la a partir de seu fundamento constitutivo ontológico. Sendo 
assim, a análise do fetichismo da tecnologia no capital é baseada no determinismo tecnológico, disseminado pelos ideólogos fatalistas e irracionalistas, bem como por autores que fazem a apologia à difundida 'sociedade tecnológica' atual. Ambas as concepções não estão calcadas na base material objetiva, pois retiram o caráter histórico da constituição da tecnologia e sua relação com o ser social.

Qualquer análise acerca da tecnologia que não privilegie o trabalho como atividade essencial da sociedade e para a complexificação tecnológica que contribuíram para a formação desta sociedade, tem sua base na efemeridade metafísica ou no irracionalismo fatalista, sendo que ambas as alternativas contribuem para a manutenção e o desenvolvimento do capitalismo no que tange à intensificação do valor. Grande parte dos autores aqui analisados concentraram seus escritos sobre tecnologia a partir de sua relação direta ao modo de produção capitalista, o que inviabilizaria quaisquer perspectivas emancipatórias relacionadas diretamente à produção de tecnologia e como esta se manifesta como categoria essencial para o desenvolvimento do ser social em termos de potencialidades. É a partir da perspectiva marxiana que pudemos desenvolver nossa análise acerca de como é produzida ideologicamente uma concepção de tecnologia particular ao modo de produção capitalista e que contribui diretamente para a valorização do valor.

Pelo fato do controle ser fator determinante para que o capital obtenha para si níveis de extração de mais-valia que garantam a sua perpetuação ad aeternum, torna-se imprescindível que a 'aplicação tecnológica da ciência' - expressão cunhada por Marx -, contribua para o aprimoramento e potencialização do controle sobre a força de trabalho. Nesse caso,

A ciência, como produto intelectual geral do desenvolvimento social,
apresenta-se assim como diretamente incorporada no capital (a aplicação
da ciência no processo material de produção, como ciência separada do
saber e da destreza dos operários considerados individualmente), - na
medida em que opera como força produtiva do capital que se defronta com
o trabalho, apresenta-se como desenvolvimento do capital, e isso tanto mais
quanto, para a grande maioria, esse desenvolvimento corre a par com o
dispêndio de capacidade de trabalho. (MARX, 1985, p.126)

O fetiche da tecnologia - ou a autonomização desta perante as relações sociais constituídas historicamente -, proporciona as condições objetivas para a 'naturalização' do controle que o capital exerce sobre a força de trabalho, característica necessária para o processo de valorização do valor. 


\section{REFERÊNCIAS}

ADORNO, Theodor W; HORKHEIMER, Max. Dialética do esclarecimento. Rio de Janeiro: Jorge Zahar, 1985.

ANTIVALOR. Cartas de Adorno e Marcuse. Disponível em <http://antivalor2.vilabol.uol.com.br/textos/frankfurt/adorno/adorno_23.html> . Acesso em 25 de agosto de 2007.

BLOCH, Ernst. Princípio esperança. 3 vol. Rio de Janeiro: Contraponto, 2005.

BRÜSEKE, Franz Josef. Heidegger como crítico da técnica moderna. Portal Filosofia da Técnica. Disponível em http://www.filoinfo.bem-vindo.net/. Acesso em: 24 de julho de 2007.

BRÜSEKE, Franz Josef. Heidegger como crítico da técnica moderna. Portal Filosofia da Técnica. Disponível em http://www.filoinfo.bem-vindo.net/. Acesso em: 24 de julho de 2007.

COCCO, Ricardo. A questão da técnica em Heidegger. 2007. 101 f. Dissertação (Mestrado em Filosofia) - Programa de Pós-Graduação em Filosofia, Universidade Vale do Rio dos Sinos - UNISINOS, São Leopoldo, 2007.

CRITELLI, Dulce. Martin Heidegger e a essência da técnica. In: Margem, n. 16, p. 83-89, São Paulo, dezembro-2002.

DELLA FONTE, Sandra Soares. As fontes heideggerianas do pensamento pósmoderno. 2006. 233 f. Tese (Doutorado em Educação) Programa de PósGraduação em Educação. Universidade Federal de Santa Catarina, Florianópolis, 2006.

DIAS, Silvano Severino; ARAÚJO, José Carlos de Souza. A concepção de educação nacional-popular em Vieira Pinto. Cadernos de História da Educação. v. 1. n. 1. jan./dez. 2002. pp. 103-108.

FEENBERG, Andrew. Marcuse ou Habermas: duas críticas da tecnologia. Disponível em: <http:www-rohan.sdsu.edu/faculty/feenberg>. Acesso em: 18 de janeiro de 2007.

FEENBERG, Andrew. Transforming Technology. Oxford: Oxford University Press, 2002.

FEENBERG, Andrew; LEISS, William. Introduction: The Critical Theory of Herbert Marcuse. In: The Essential Marcuse: Selected Writings of Philosopher and Social Critic Herbert Marcuse. Toronto: Beacon Press, 2007. 
FREITAS, Marcos Cezar de. Economia e educação: a contribuição de Álvaro Vieira Pinto para o estudo histórico da tecnologia. in: Revista Brasileira de Educação. v. 11. n. 31. jan./abr. 2006.

GUIMARÃES, Valeska Nahas. Novas tecnologias de produção de base microeletrônica e democracia industrial: um estudo comparativo de casos na indústria mecânica de Santa Catarina, Tese (Doutorado em Engenharia de Produção e Sistemas). Programa de Pós-Graduação em Engenharia de Produção e Sistemas, Universidade Federal de Santa Catarina, Florianópolis, 1995.

HABERMAS, Jürgen. Técnica e ciência como ideologia. Lisboa: Edições 70, 2001.

HARVEY, David. Condição pós-moderna: uma pesquisa sobre as origens da mudança cultural. 17. ed. São Paulo: Edições Loyola, 2008.

HEIDEGGER, Martin. A questão da técnica. In: Cadernos de tradução, n. 2, DF/USP, 1997.

HERF, Jeffrey. Modernismo reacionário: tecnologia, cultura e política na República de Weimar e no Terceiro Reich. São Paulo/Campinas: Ensaio/Editora da Universidade Estadual de Campinas, 1993.

KOSIK, Karel. Dialética do concreto. 7. ed. Rio de Janeiro: Paz e Terra, 2002.

LEOPOLDO E SILVA, Franklin. Martin Heidegger e a técnica. Scientiæ Studia, São Paulo, v. 5, n. 3, p. 369-74, 2007

LOUREIRO, Isabel. Herbert Marcuse: a relação entre teoria e prática. In: LOUREIRO, Isabel; MUSSE, Ricardo (orgs). Capítulos do marxismo ocidental. São Paulo: Fundação Editora da UNESP,1998.

LOUREIRO, Isabel. Herbert Marcuse: anticapitalismo e emancipação. In: Trans/Form/Ação, n. 28, pp. 07-20, São Paulo, 2005.

LUKÁCS. György. El asalto a la razón: la trayectoria del irracionalismo desde Schelling hasta Hitler. 2. ed. Barcelona-México: Ediciones Grijalbo, 1968.

LUKÁCS. György. Tecnologia e relações sociais. In: BERTELLI, Antonio R. (org.). Bukhárin: teórico marxista. Belo Horizonte: Oficina do Livro, 1989.

MARCUSE, Herbert . Eros e Civilização: uma interpretação filosófica do pensamento de Freud. 6. ed. Rio de Janeiro: Zahar,1975.

MARCUSE, Herbert. Ideologia da sociedade industrial: o homem unidimensional. Rio de Janeiro: Zahar Editores, 1967.

MARCUSE, Herbert. Industrialização e capitalismo em Max Weber. Disponível em:

<http://antivalor.vilabol.uol.com.br/textos/frankfurt/marcuse/tx_marcuse_001.htm> Acesso em: 22 de maio de 2006. 
MARCUSE, Herbert. Liberdade e Agressão na Sociedade Tecnológica. Civilização Brasileira, n. 18, ano 3, março-abril, 1968. Disponível em:

$<$ http://antivalor.vilabol.uol.com.br/textos/frankfurt/marcuse/tx_marcuse_004.htm> Acesso em: 22 de maio de 2006.

MARX, Karl. Consequências sociais do avanço tecnológico. São Paulo: Edições Populares, 1980.

MARX, Karl. O Capital: crítica da economia política. Livro III. vol. II. São Paulo: Abril Cultural, 1985.

MÉSZARÓS, István. O poder da ideologia. São Paulo: Boitempo, 2004.

MÉSZARÓS, István. Para além do capital: rumo a uma teoria da transição. São Paulo: Boitempo, 2002.

MIRANDA, Angela Luzia. Da natureza da tecnologia: uma análise filosófica sobre as dimensões ontológica, epistemológica e axiológica da tecnologia moderna. 2002. 153 f. Dissertação (Mestrado em Tecnologia) Programa de Pós-Graduação em Tecnologia. Centro Federal de Educação Tecnológica do Paraná.

NOGUEIRA, Paulo Henrique. Habermas e a não centralidade formativa do trabalho: uma crítica filosófica ao marxismo. Disponível em: <http:www.infoamerica.org/documentos_pdf/habermas04.pdf>. Acesso em: 27 de agosto de 2008.

NOVAES, Henrique Tahan. O fetiche da tecnologia: a experiência das fábricas recuperadas. São Paulo: Expressão Popular, 2007.

ORGANISTA, José Henrique Carvalho. $\mathbf{O}$ debate sobre a centralidade do trabalho. São Paulo: Expressão Popular, 2006.

TOLEDO, Caio Navarro de. Intelectuais e política no Brasil. A experiência do ISEB. Rio de Janeiro: Revan, 2005.

TRAGTENBERG, Maurício. Burocracia e ideologia. 4. ed. São Paulo: Ática, 1985.

VIEIRA PINTO, Álvaro. O conceito de tecnologia. vol. I. Rio de Janeiro: Contraponto, 2005.

Artigo:

Recebido em: 22/09/2011

Aceito em: 10/11/2011 